Foss. Rec., 21, 119-135, 2018

https://doi.org/10.5194/fr-21-119-2018

(C) Author(s) 2018. This work is distributed under

the Creative Commons Attribution 4.0 License.

\title{
New information on the Cenomanian bothremydid turtle Algorachelus based on new, well-preserved material from Spain
}

\author{
Adán Pérez-García \\ Grupo de Biología Evolutiva, Facultad de Ciencias, UNED, Paseo de la Senda del Rey 9, 28040 Madrid, Spain \\ Correspondence: Adán Pérez-García (paleontologo@gmail.com)
}

Received: 3 November 2017 - Revised: 13 February 2018 - Accepted: 13 March 2018 - Published: 13 April 2018

\begin{abstract}
Algorachelus peregrinus is the oldest representative of the crown group Pleurodira known in Laurasia. The type locality of this bothremydid is Algora, situated in central Spain, at levels deposited during the uppermost middlelowermost upper Cenomanian. A new excavation was recently carried out in this town. As a result, abundant material of Algorachelus peregrinus has been found. Several complete shells, as well as numerous partial carapaces and plastra, are presented here. The abundance of remains allows the analysis of the general patterns by which some of the shells of this littoral form were partially or totally disarticulated. The analysis of these remains not only shows several pathologies but also improves the knowledge about the anatomy and intraspecific variability of Algorachelus peregrinus. This new information allows the revision of other Cenomanian forms of Bothremydidae, both from the Middle East and from North America. Thus, Algorachelus is identified in these regions, being represented in the early or middle Cenomanian of Palestine by the new combination Algorachelus parvus, and in the uppermost Cenomanian of Utah by the new combination Algorachelus tibert. Therefore, a relatively fast and widely distributed geographic dispersion event is recognized, corresponding to the oldest dispersal event so far identified for a lineage of Pleurodira from Gondwana to Laurasia.
\end{abstract}

\section{Introduction}

Pleurodira is a well-represented group of turtles in the uppermost Cretaceous and Eocene records of Europe. Thus, several Gondwanic lineages of Bothremydidae and Podocnemididae reached this continent through diachronic dispersion events (Lapparent de Broin, 2001; Pérez-García, 2017a;
Pérez-García et al., 2017a, b). The oldest representative of Pleurodira known in a Laurasiatic region was defined in the Iberian Peninsula. It is the Bothremydid Algorachelus peregrinus Pérez-García, 2016, whose type locality is located in the uppermost middle-lowermost upper Cenomanian levels of Algora (Guadalajara, Spain). A partial shell of this taxon was recently found at synchronous levels of the Portuguese record, in the middle Cenomanian of Nazaré (Pérez-García et al., 2017a).

The type material of Algorachelus peregrinus was found during the first systematic excavation carried out in Algora, in which the objective was the evaluation of the potential interest of the fossiliferous levels (Pérez-García et al., 2013; Pérez-García, 2016). Therefore, that was a short field campaign but through which the interest of this fossil locality was confirmed, as well as the need for a future intervention. A new excavation was carried out in November 2016 (Fig. 1). As a consequence, abundant material, especially of the turtle Algorachelus peregrinus, was found (Figs. 2-8). A single relatively complete carapace from Algora was known, corresponding to the holotype of that taxon (see Pérez-García, 2016). In addition to a partial skull and several isolated appendicular elements, a fragment of carapace, partial carapaces and plastra, and several disarticulated plates had been described (Pérez-García, 2016). The new material presented here corresponds to several complete or almost complete and very well-preserved shells, as well as to abundant articulated remains of both the carapace and the plastron. The study of these new fossils improves the knowledge about the anatomy of the shell in this form, its possible phylogenetic closeness with other Cenomanian species from both the Middle East and North America being evaluated.

The information provided by the previously found specimens and, especially, by these new remains, allows me to 

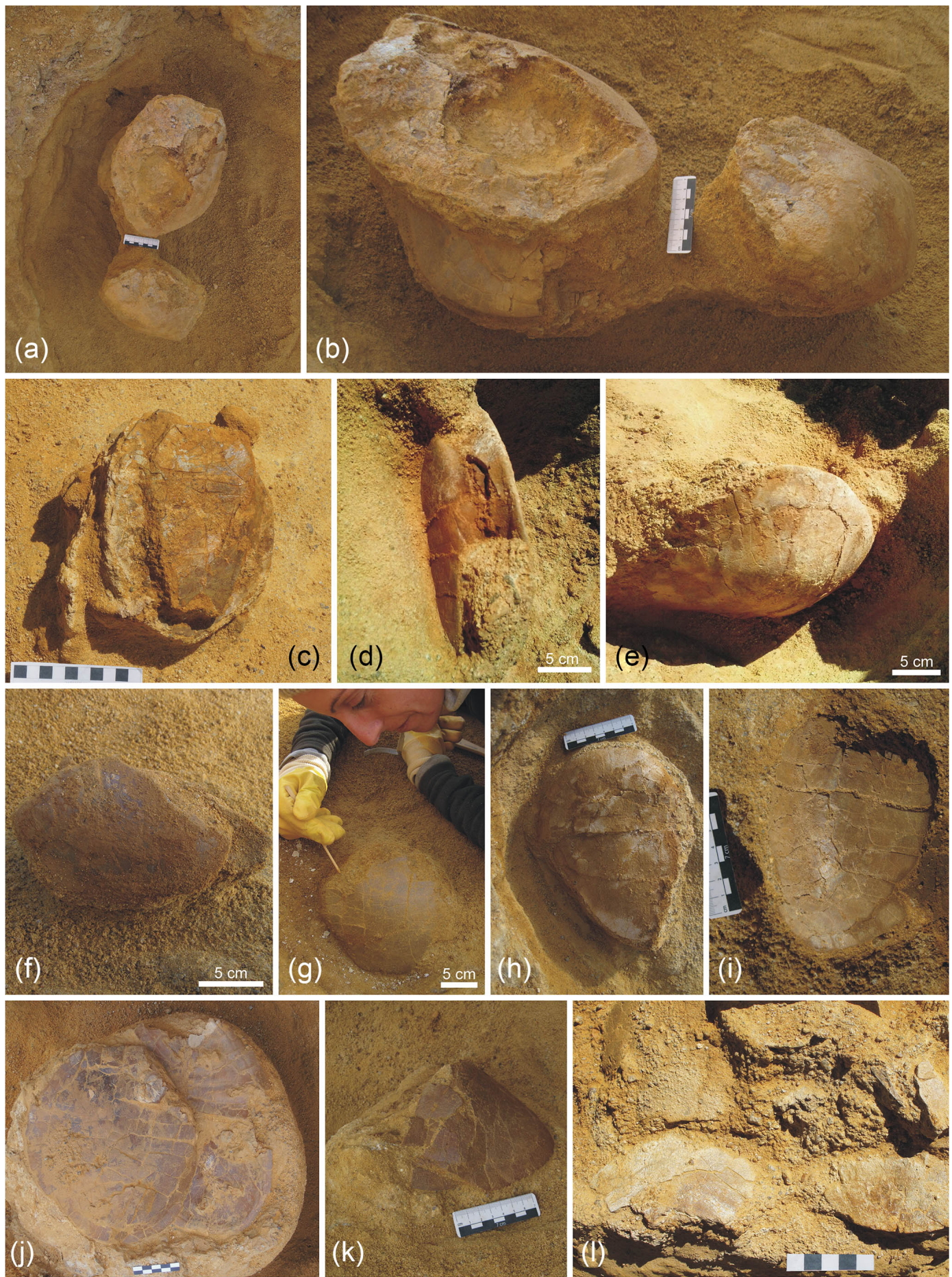

Figure 1. Some specimens of Algorachelus peregrinus (Pleurodira, Bothremydidae), in situ, during the excavations performed in the Cenomanian levels of Algora (Guadalajara, Spain). (a-b) Shells ALG 76 (see Fig. 3c-d), ALG 77 (see Fig. 3e-f) and ALG 133 (see Fig. 8a-c), in zenithal (a) and latero-zenithal (b) views (this and the other views indicated in this figure caption are those relative to the plane of stratification, and, therefore, not in relation to the anatomy of turtles, unlike those in the other captions). (c) ALG 1, holotype of the taxon, in zenithal view. (d-e) Shell ALG 75 (see Fig. 3a-b), in zenithal (d) and latero-zenithal (e) views. (f) Shell ALG 73 (see Fig. 2e-f), in latero-zenithal view. (g) Partial carapace ALG 95 (see Fig. 5o), in latero-zenithal view. (h) Shell ALG 74 (see Fig. 2g-h), in zenithal view. (i) Partial carapace ALG 93 (see Fig. 5m), in zenithal view. (j) Specimen ALG 80, composed of three individuals, a complete shell and two partial carapaces (see Fig. 4d-e), in zenithal view. (k) Partial shell ALG 79 (see Fig. 4b-c), in latero-zenithal view. (l) Detail of the basal area of the fossiliferous level, where the remains of turtles, generally corresponding to partial plates, disjointed plates, and partial carapaces or plastra, are very common; in zenithal view. 


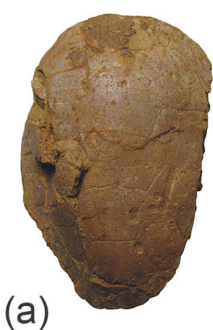

(a)

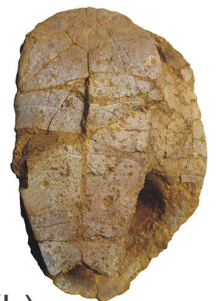

(b)

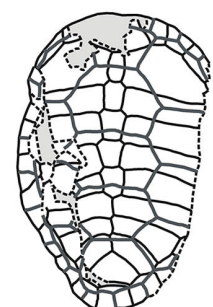

(a')

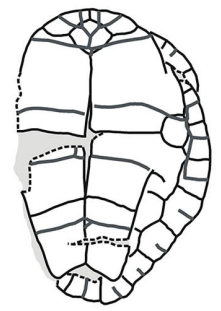

(b')

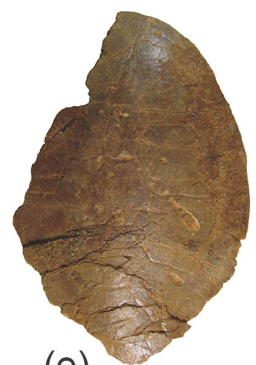

(e)

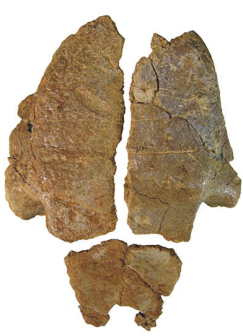

(f)

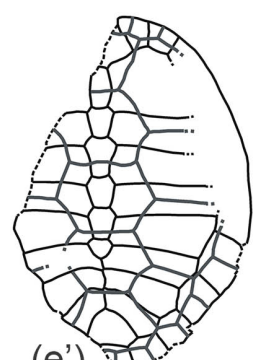

$\left(e^{\prime}\right)$

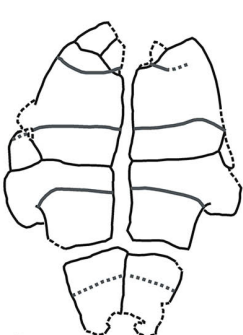

$\left(f^{\prime}\right)$

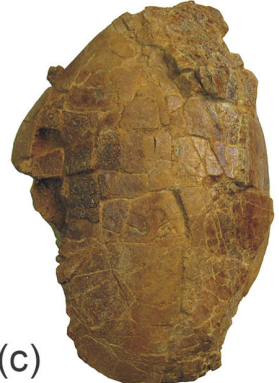

(c')

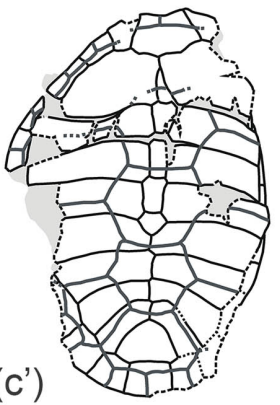

$\left(d^{\prime}\right)$
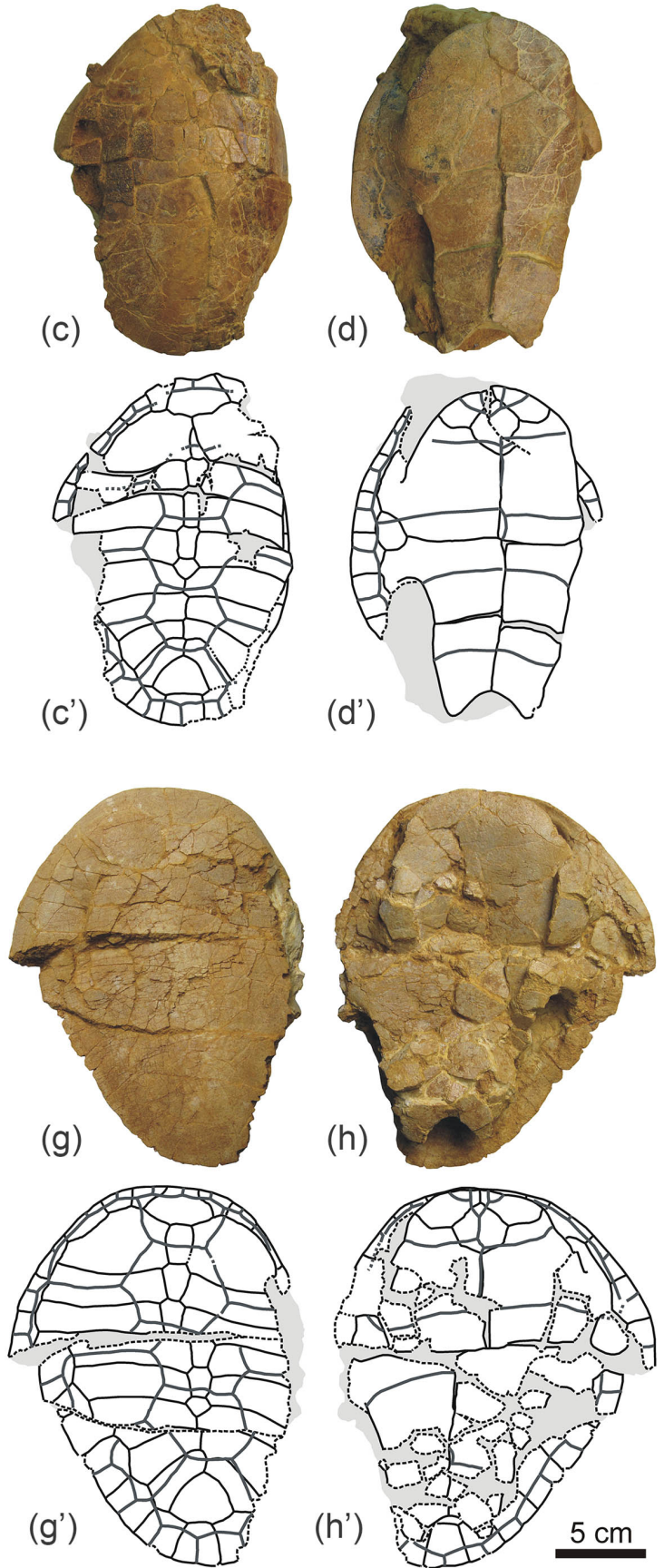

Figure 2. Shells of Algorachelus peregrinus (Pleurodira, Bothremydidae), from the Cenomanian of Algora (Guadalajara, Spain). (a-b) ALG 71 in dorsal (a) and ventral (b) views. (c-d) ALG 72 in dorsal (c) and ventral (d) views. (e-f) ALG 73 in dorsal (e) and ventral (f) views. (g-h) ALG 74 in dorsal (g) and ventral (h) views.

analyze which have been the main patterns of disarticulation that affected some of the shells of this coastal turtle. In addition, several pathologies are detected in the shells of Algorachelus peregrinus.

\section{Institutional abbreviations}

ALG, Algora collection, deposited in the Museo de Paleontología de Castilla-La Mancha, Cuenca, Spain; DCT, Departamento de Ciências da Terra da Universidade de Coimbra, Coimbra, Portugal. 


\section{Systematic paleontology}

Testudines Batsch, 1788

Pleurodira Cope, 1864

Pelomedusoides Cope, 1868

Bothremydidae Baur, 1891

Bothremydini Gaffney, Tong and Meylan, 2006

Algorachelus Pérez-García, 2016

Algorachelus peregrinus Pérez-García, 2016

Figs. 2-8

Material: 68 specimens, ALG 71 to ALG 138, corresponding to shells and partial carapaces and plastra found at the site ALG-B (as the type series of this taxon) during the excavation carried out in November 2016 (Figs. 1a-b, d-1, 2-8)

Locality and horizon: Site ALG-B, Algora Municipality, Guadalajara Province, Castilla-La Mancha Autonomous Community, Castilian Branch of the Iberian Ranges, central Spain. Upper part of the Arenas de Utrillas Formation. Uppermost middle-lowermost upper Cenomanian (Torices et al., 2012; Pérez-García, 2016).

Description: Eleven of the specimens presented here correspond to shells (i.e., individuals preserving both the carapace and the plastron) (Figs. 2-4, 8a-b). Most of them are articulated and complete or almost complete (Figs. 2a-d, $\mathrm{g}-\mathrm{h}, 3 \mathrm{a}-\mathrm{f}, 4 \mathrm{~d}-\mathrm{e}, 8 \mathrm{a}-\mathrm{b})$. Although ALG 73 shows the almost complete and articulated carapace, its plastron is not articulated with it, being divided into three parts (Fig. 2e-f). A large part of the carapace of ALG 78 is not preserved due to the weathering (Fig. 4a). Some regions of both the carapace and the plastron of ALG 79 were disarticulated and lost before its burial (Fig. 4b-c). The complete shell in ALG 80 is preserved in a block that also includes remains of two other individuals, corresponding to the posterior half of two carapaces (Fig. 4e). Although many of these specimens are recognized as adult individuals, some are identified as juvenile due to their remarkably lower size. Thus, the length of the complete shell ALG 71, corresponding to the smallest of those recognized in the site, is $113 \mathrm{~mm}$ (Fig. 2a-b), but that of the larger (i.e., ALG 77, Fig. 3e-f) is $262 \mathrm{~mm}$.

Several partial and articulated carapaces are analyzed (Figs. 4e, 5, 6, 8d-j). Some of them correspond to relatively complete carapaces (e.g., Fig. 5n), but a smaller number of plates is preserved in others (e.g., very few elements are preserved in Fig. 6t). In addition, several articulated plastra are analyzed (Fig. 7), also including some relatively complete (e.g., Fig. 7p), but others corresponding to partial or very partial ones (e.g., Fig. 7j). In addition, several of the specimens show breaks, in most cases being pre-depositional (i.e., generated during the biostratinomic phase).
The morphology of the shell, plates and scutes of $A l$ gorachelus peregrinus was described in detail by PérezGarcía (2016). Some of the new specimens allow expanding the knowledge about its intraspecific variability (see Discussion). In addition, several pathologies are recognized (see Discussion and Fig. 8).

\section{Discussion}

\subsection{Anatomical implications and identification of anomalies}

All specimens analyzed here come from the type locality and horizon of Algorachelus peregrinus. They can be attributed to this taxon, the presence of a single representative of Bothremydidae being confirmed for this locality. Thus, they share the exclusive combination of shell characters that allows one to diagnose this form (see Pérez-García, 2016): very shallow nuchal notch; wider than long nuchal, its anterior margin being equal to or greater than half of the maximum width of the plate; neural series composed of five to seven neurals; anterolateral region of the first vertebral on the first pair of peripherals or reaching the second; each scute of the first pair of marginals much wider than long; overlap of the first pair of marginals on no more than half of the nuchal anterolateral margin; medial contact of the humerals; absence of overlap of the pectorals on the epiplastra; overlap of the pectorals on the entoplastron; pectoro-abdominal sulci crossing the mesoplastra.

Algorachelus peregrinus was diagnosed as a relatively small form, the maximum length of the shell of the previously known specimens being less than $250 \mathrm{~mm}$. The hypothesis proposing a relatively small size for this species is here confirmed, although a slightly larger size is identified for one specimen, ALG 77 (Fig. 3e-f), whose length is $262 \mathrm{~mm}$.

Only a relatively complete shell of Algorachelus peregrinus had been, until now, recognized in its locality type (the holotype). This specimen allowed interpreting that the anterior margin of the plastron of this species probably reaches a level close to that of the anterior carapace margin (PérezGarcía, 2016). A partial carapace also attributed to this species was recently found in the middle Cenomanian levels of Nazaré (Portugal), DCT-NZV30 (see Pérez-García et al., 2017a). Although the most anterior region of its plastron was not preserved (i.e., neither the entoplastron nor the epiplastra), the position of the anterior margin of the hyoplastra supported this hypothesis. It can be confirmed here by all the new shells in which the anterior margin of both the carapace and the plastron are preserved (see Figs. 2, 3, 4d-e, 8a-b).

The identification of numerous specimens preserving the complete neural series, or at least the posterior region of the carapace in which the number of costals with sagittal contact is recognized, allows me to confirm the variability previously detected relative to the number of neurals (see Pérez-García, 

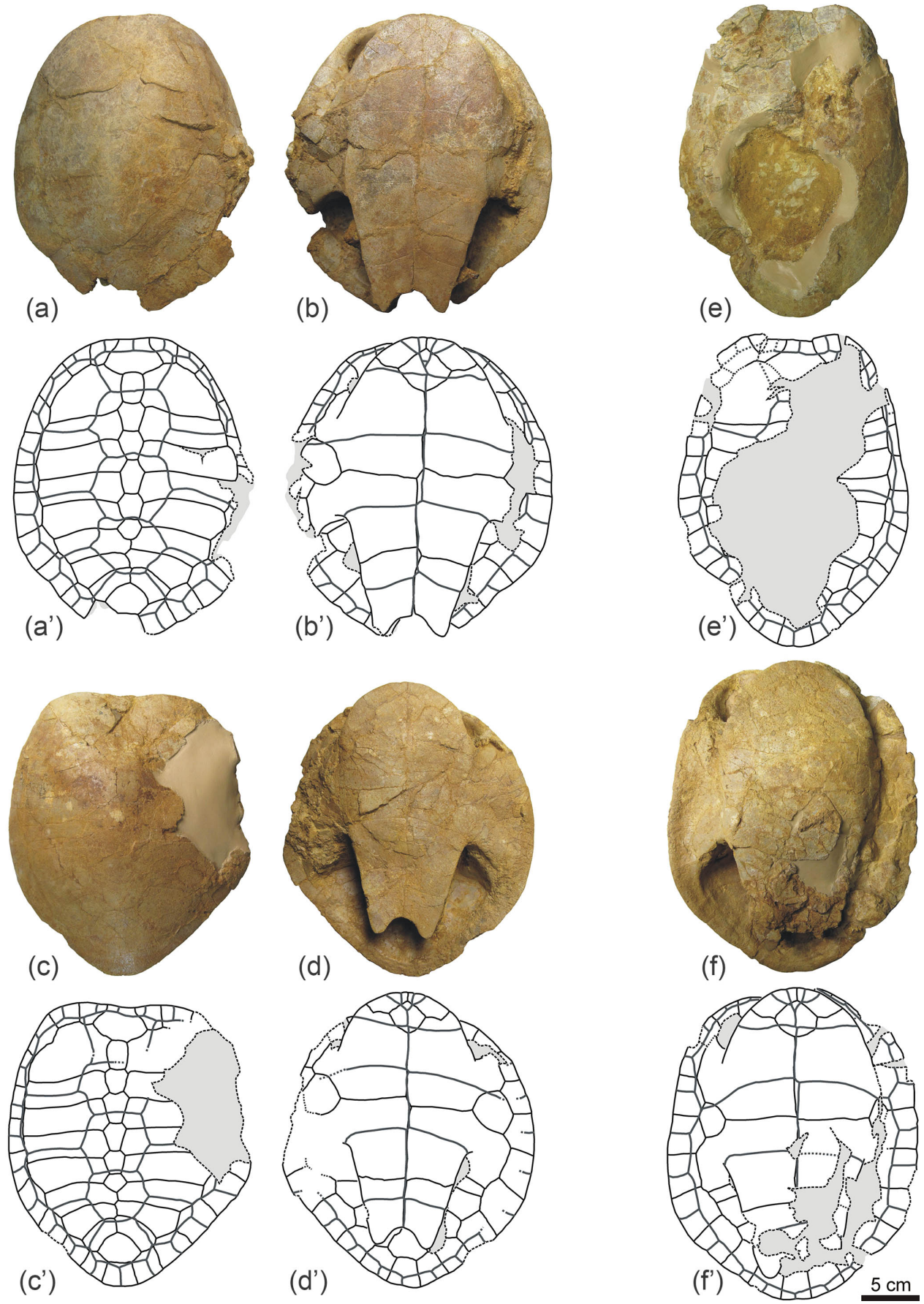

Figure 3. Shells of Algorachelus peregrinus (Pleurodira, Bothremydidae), from the Cenomanian of Algora (Guadalajara, Spain). (a-b) ALG 75 in dorsal (a) and ventral (b) views. (c-d) ALG 76 in dorsal (c) and ventral (d) views. (e-f) ALG 77 in dorsal (e) and ventral (f) views.

2016). Most of these new specimens show the medial contact of the last three pairs of costals, the neural series being composed of six plates ( 25 individuals). In fact, this was the most common condition for the previously known material from this locality, being also shared with the Portuguese shell (see Pérez-García et al., 2017a). Seven neurals are identified in ALG 134 (Fig. 8d) and ALG 138 (Fig. 8j), the posterior me- dial contact of the costal series being restricted to the last two pairs of plates. The reduction of the neural series, being composed of five plates, is only present in ALG 71 (Fig. 2ab) and ALG 72 (Fig. 2c-d). However, the medial contact of the fifth to eighth costals occurs in ALG 72, but only that of the last three costals in ALG 71. This is due to the fact that although the morphology of the last neural of ALG 72 is 

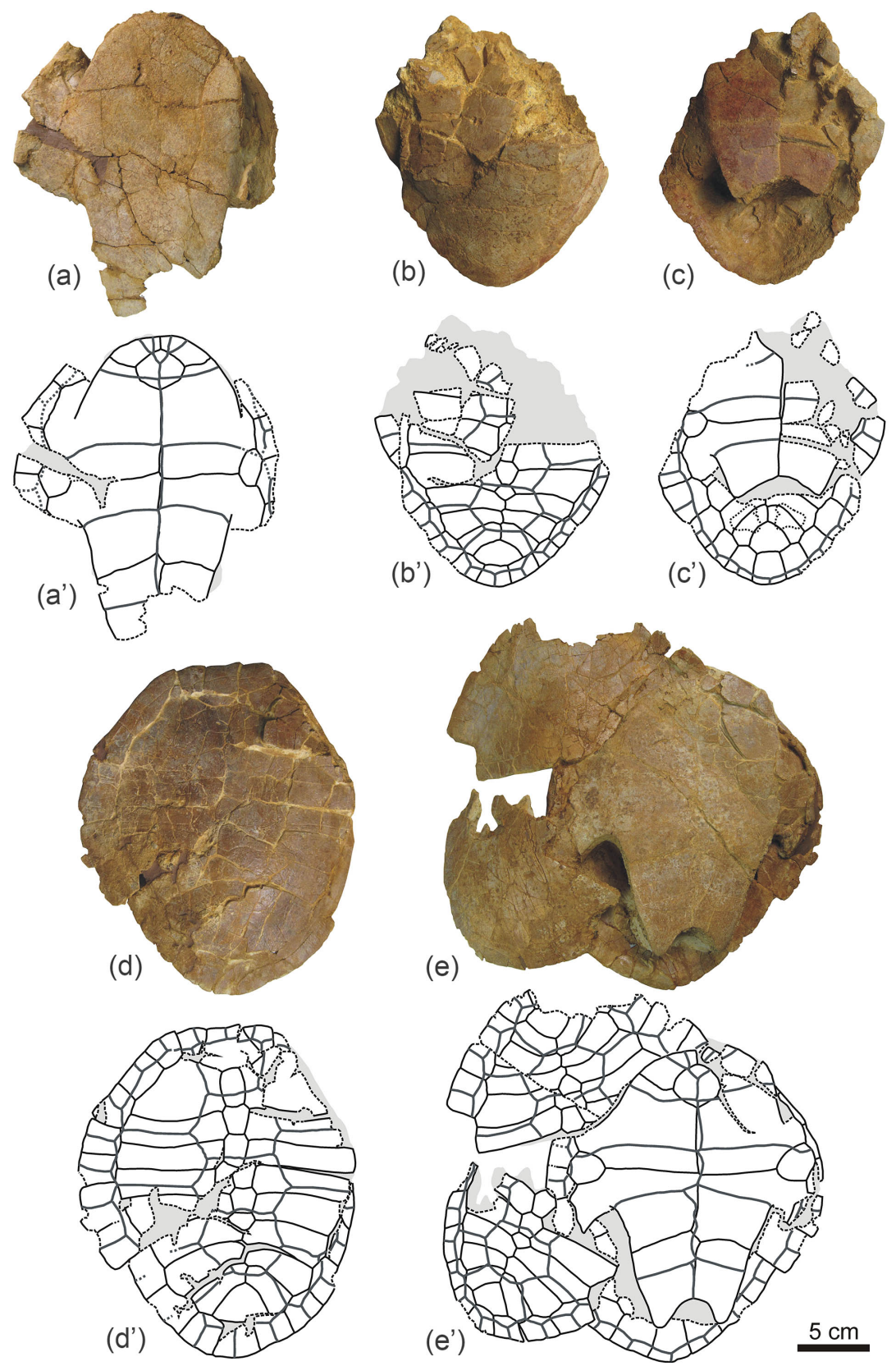

Figure 4. Shells of Algorachelus peregrinus (Pleurodira, Bothremydidae), from the Cenomanian of Algora (Guadalajara, Spain). (a) ALG 78 in ventral (h) view. (b-c) ALG 79 in dorsal (b) and ventral (c) views. (d-e) ALG 80 in dorsal (d) and ventral (e) views. The posterior region of two partial carapaces are also available in $(\mathbf{e})$, all of them in dorsal view.

pentagonal, as wide as it is long (as in most representatives of Algorachelus peregrinus), that of ALG 71 has an anomalous morphology, being heptagonal, notably longer than wide.

Algorachelus peregrinus has a continuous neural series. A single specimen of those hitherto known showed an exception, ALG 39 (see fig. 5b'-d' in Pérez-García, 2016), in which a short medial contact between the fifth costals was identified, located between the last two neurals. The same situation is recognized here for ALG 104 (Fig. 6h). The pen- tagonal neural is not the last in any of these two specimens, in contrast to the situation known for the other individuals of this taxon. It is the fifth. Thus, the sixth neural is rhombic. A similar situation is identified in ALG 134 (Fig. 8d), but, because seven neurals are present in this individual, the short medial contact occurs between the sixth and seventh neurals, the sixth being the pentagonal, and the seventh the rhombic.

In addition to the unique morphology and arrangement of the neural series of ALG 134 (Fig. 8d), this partial cara- 


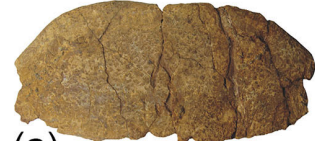

(a)

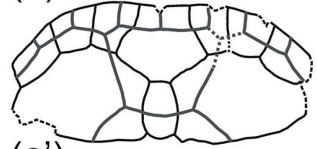

(a')

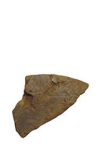

(f)

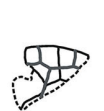

$\left(f^{\prime}\right)$

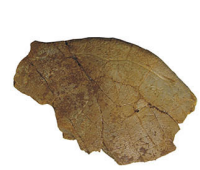

(g)

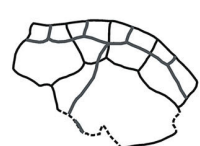

$\left(g^{\prime}\right)$

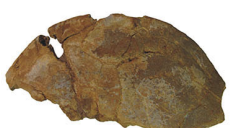

(b)

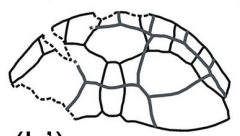

(b')

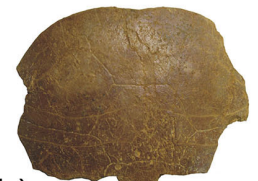

(h)

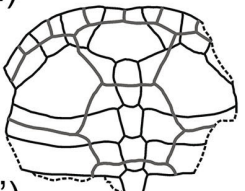

(c)
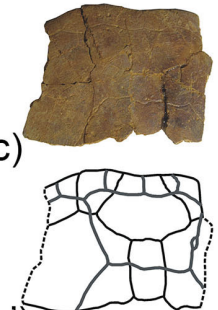

(c')

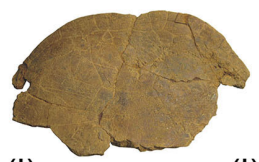

(i)

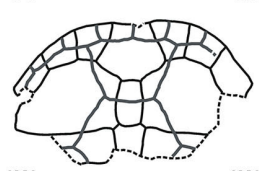

(i')

(d)

(j) (d)
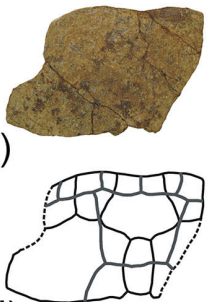

(d')
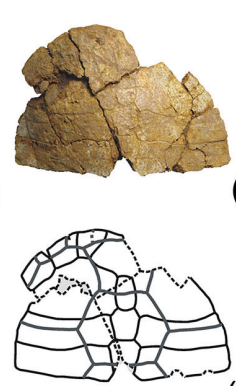

(j')

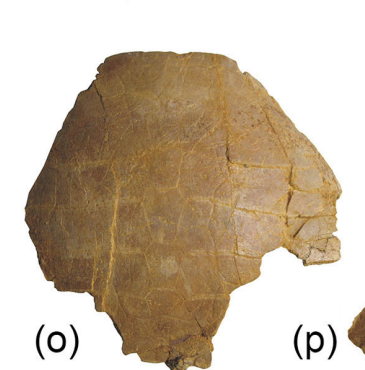

(k')

(p) (e)

(e')
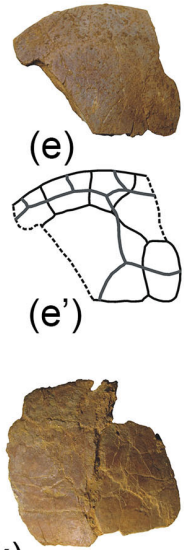

(k)

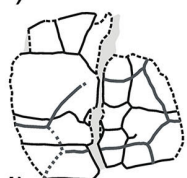

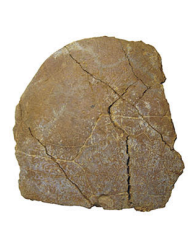

(I)

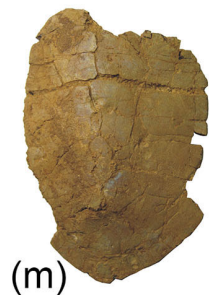

(m')

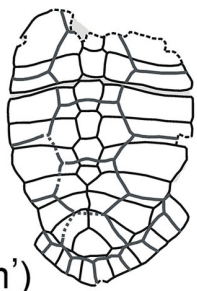

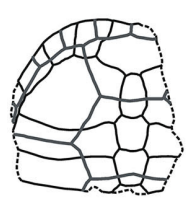

(l') (n)

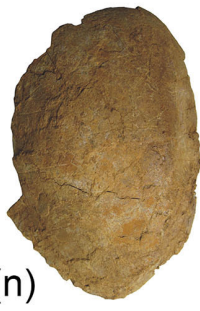

(n')

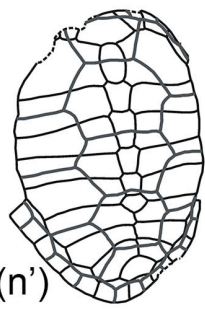

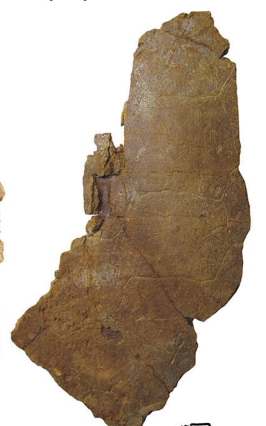

\section{$5 \mathrm{~cm}$}
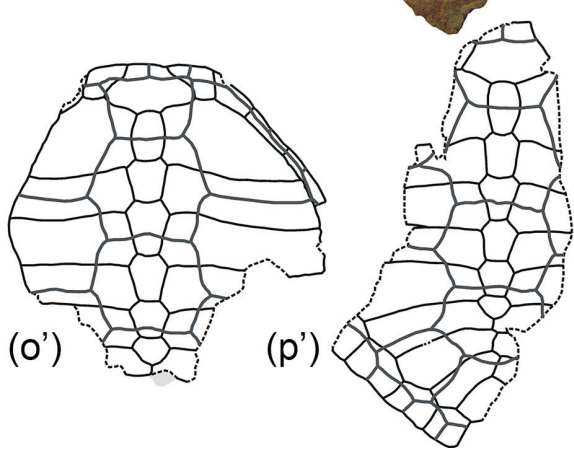

Figure 5. Partial carapaces of Algorachelus peregrinus (Pleurodira, Bothremydidae), from the Cenomanian of Algora (Guadalajara, Spain). All of them are in dorsal view. (a) ALG 81; (b) ALG 82; (c) ALG 83; (d) ALG 84; (e) ALG 85; (f) ALG 86; (g) ALG 87; (h) ALG 88; (i) ALG 89; (j) ALG 90; (k) ALG 91; (l) ALG 92; (m) ALG 93; (n) ALG 94; (o) ALG 95; (p) ALG 96.

pace shows several anomalies, both osseous and related to the scutes. Algorachelus peregrinus has a single suprapygal plate. However, that specimen presents a very small supernumerary plate, limited by the anterior region of the suprapygal and by the postero-medial margin of the last pair of costals. The scutes of the preserved region are asymmetric. A standard contact is identified between the fourth right pleural scute and the fifth vertebral, located on the eighth costal, as occurs in the other representatives of this taxon. However, a supernumerary pleural is present in the left half, located between the fourth pleural and the fifth vertebral. Thus, the posterior margin of the fourth left pleural is not located on the eighth costal, but on the seventh. In some specimens the bone anomalies have no influence on the scutes. Thus, ALG 135 shows the complete fusion of the last neural with the sixth right costal, the scutes located on that region having the common morphology and disposition for this taxon (Fig. 8e). The morphology of the neurals preserved in ALG 137, prob- 


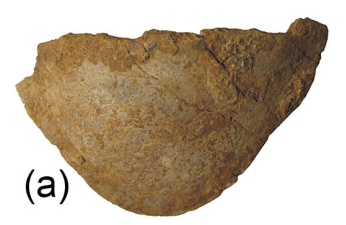

(b)
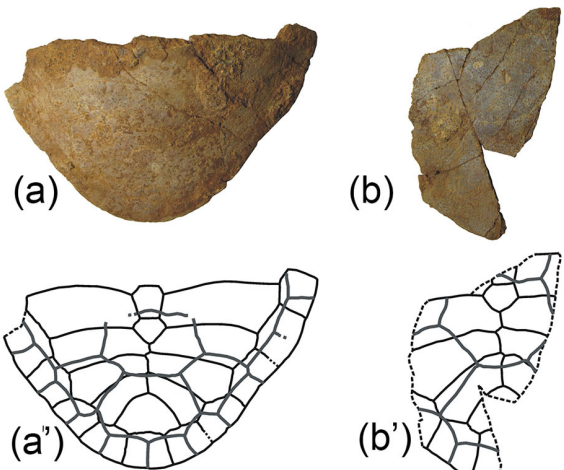

(b') (c)

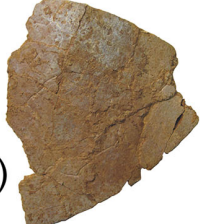

(d)

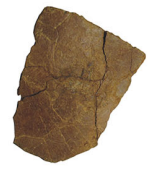

(e)
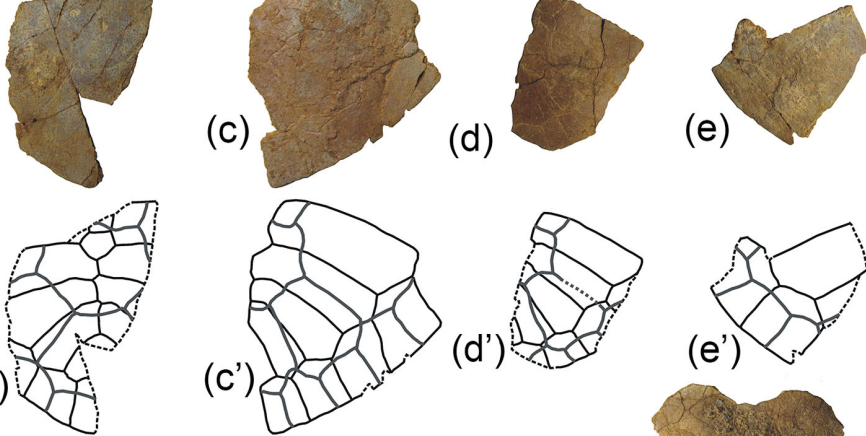

$\left(c^{\prime}\right)$

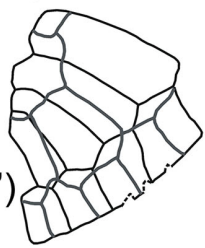

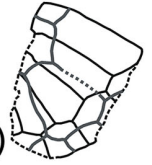

(e')

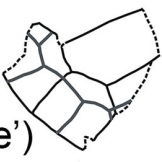

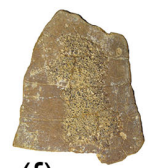

(f)

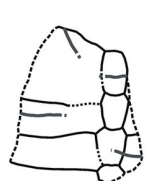

(f')

$\left(g^{\prime}\right)$

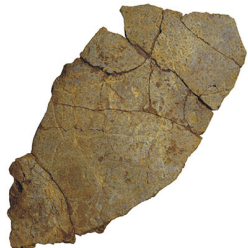

(h)
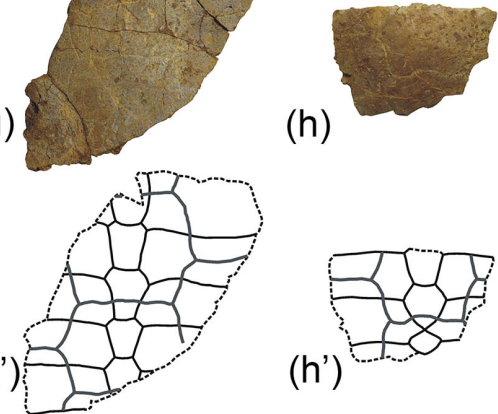

(h')

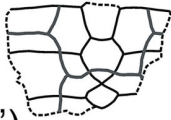

(i)

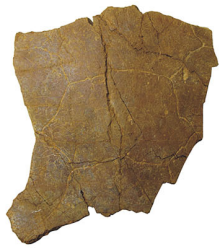

(j)

(i')

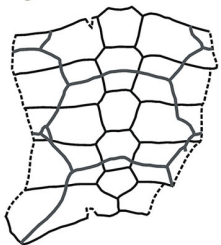

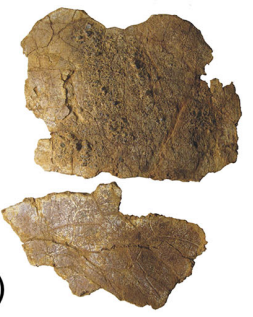

(j')

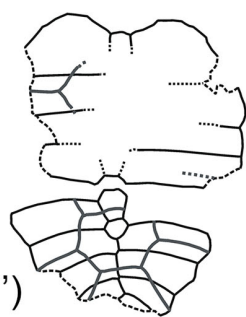

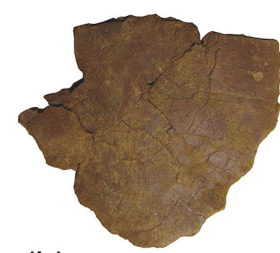

(k)

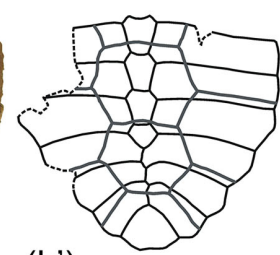

(k')
(I)

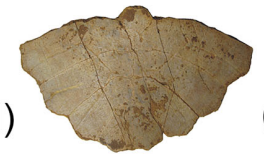

(m)

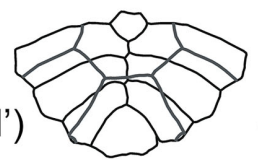

(0)

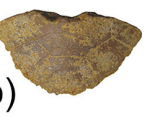

(o')

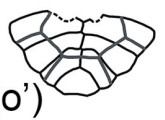

(p)

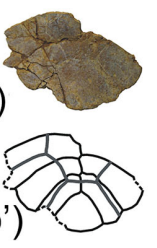

(q)

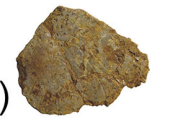

(r)

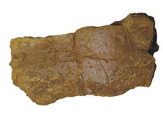

(q')
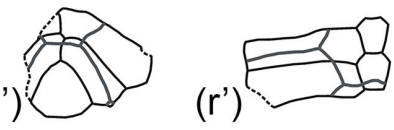

(s)

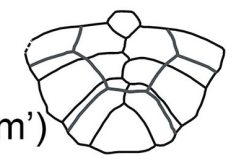

(n)

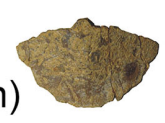

(n')

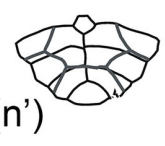

(t)

(s')

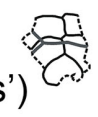

(t')

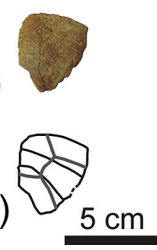

Figure 6. Partial carapaces of Algorachelus peregrinus (Pleurodira, Bothremydidae), from the Cenomanian of Algora (Guadalajara, Spain). All of them are in dorsal view. (a) ALG 97; (b) ALG 98; (c) ALG 99; (d) ALG 100; (e) ALG 101; (f) ALG 102; (g) ALG 103; (h) ALG 104; (i) ALG 105; (j) ALG 106; (k) ALG 107; (l) ALG 108; (m) ALG 109; (n) ALG 110; (o) ALG 111; (p) ALG 112; (q) ALG 113; (r) ALG 114; (s) ALG 115; (t) ALG 116.

ably corresponding to the second to fourth ones, are anomalous (Fig. 8h-i). The last of the three identified neurals is subhexagonal, with the anterolateral margins shorter than the postero-lateral, as is the common condition for this taxon. However, the others are anomalous. The most anterior is noticeably wider than long, with anterolateral margins longer than the postero-lateral. The other is anteriorly very wide in relation to the posterior region. The costal series is also anomalous, and a supernumerary plate is located between the two anterior neurals and the adjacent costals. Viscerally, the medial regions of both ribs, which have an anomalous thickening, are located on this supernumerary plate.

The scutes of most specimens where important alterations in the morphology of the plates are identified also show anomalies. ALG 136 corresponds to the middle region of a carapace, in which many of the sutures between the neu- 


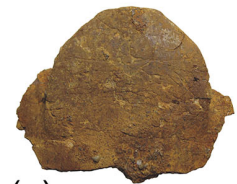

(a)

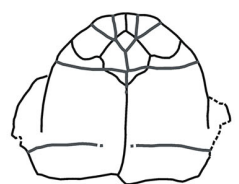

(a')

(g)

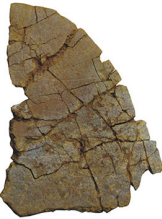

(l)

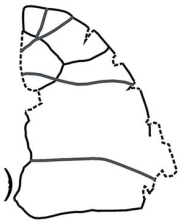

(b)

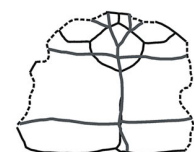

(b')

(h)

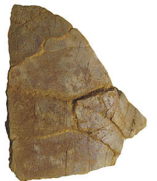

(i)

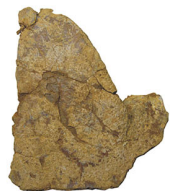

(h')

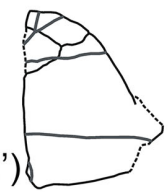

(c)

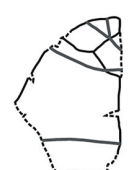

(c')

(d')

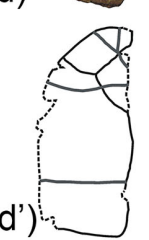

(e)
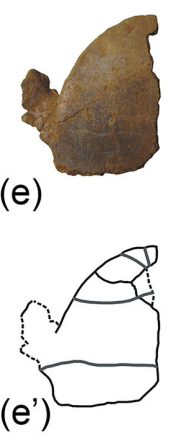

(f)

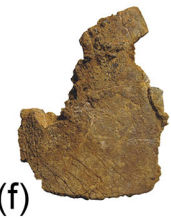

(f')

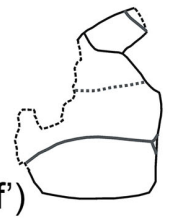

(j)

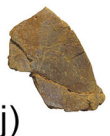

(k)

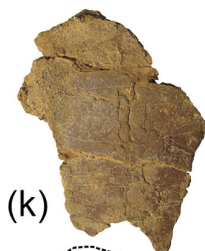

$\left(k^{\prime}\right)$

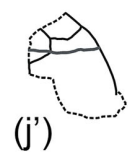

(o)

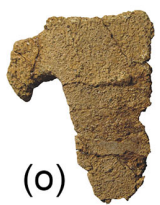

(p)

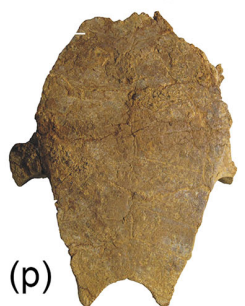

(n)

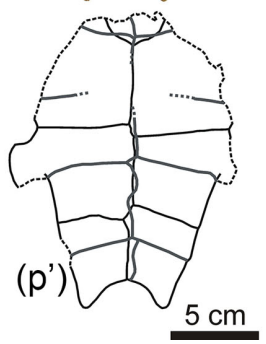

Figure 7. Partial plastra of Algorachelus peregrinus (Pleurodira, Bothremydidae), from the Cenomanian of Algora (Guadalajara, Spain). All of them are in ventral view. (a) ALG 117; (b) ALG 118; (c) ALG 119; (d) ALG 120; (e) ALG 121; (f) ALG 122; (g) ALG 123; (h) ALG 124; (i) ALG 125; (j) ALG 126; (k) ALG 127; (l) ALG 128; (m) ALG 129; (n) ALG 130; (o) ALG 131; (p) ALG 132.

rals and the costals are fully merged (Fig. 8f-g). A marked asymmetry is identified, even viscerally, in the line corresponding to the neural arches, which instead of being straight presents several undulations (Fig. 8g). Supernumerary vertebral and pleural scutes are recognized, which are also asymmetric (Fig. 8f). ALG 138, as has been indicated, presents a supernumerary neural in relation to the normal condition for Algorachelus peregrinus (Fig. 8j). Numerous anomalies are identified in the scutes of the preserved region. Not only the vertebral scutes show asymmetries, but the last right pleural has contact with the left. This right pleural is a supernumer- ary scute, the contact between the third and fourth pleurals not being located on the sixth right costal, but on the fifth. Both the last pair of costals of the shell ALG 133 and the morphology of its suprapygal are anomalous and markedly symmetrical (Fig. 8a). Several supernumerary scutes are located on the posterior region of this carapace, affecting the vertebral, pleural and marginal series. In visceral view, the plastron of this specimen shows a pair of circular and anomalous osseous growths, one larger than the other, located on the left hyoplastron (Fig. 8b-c). 

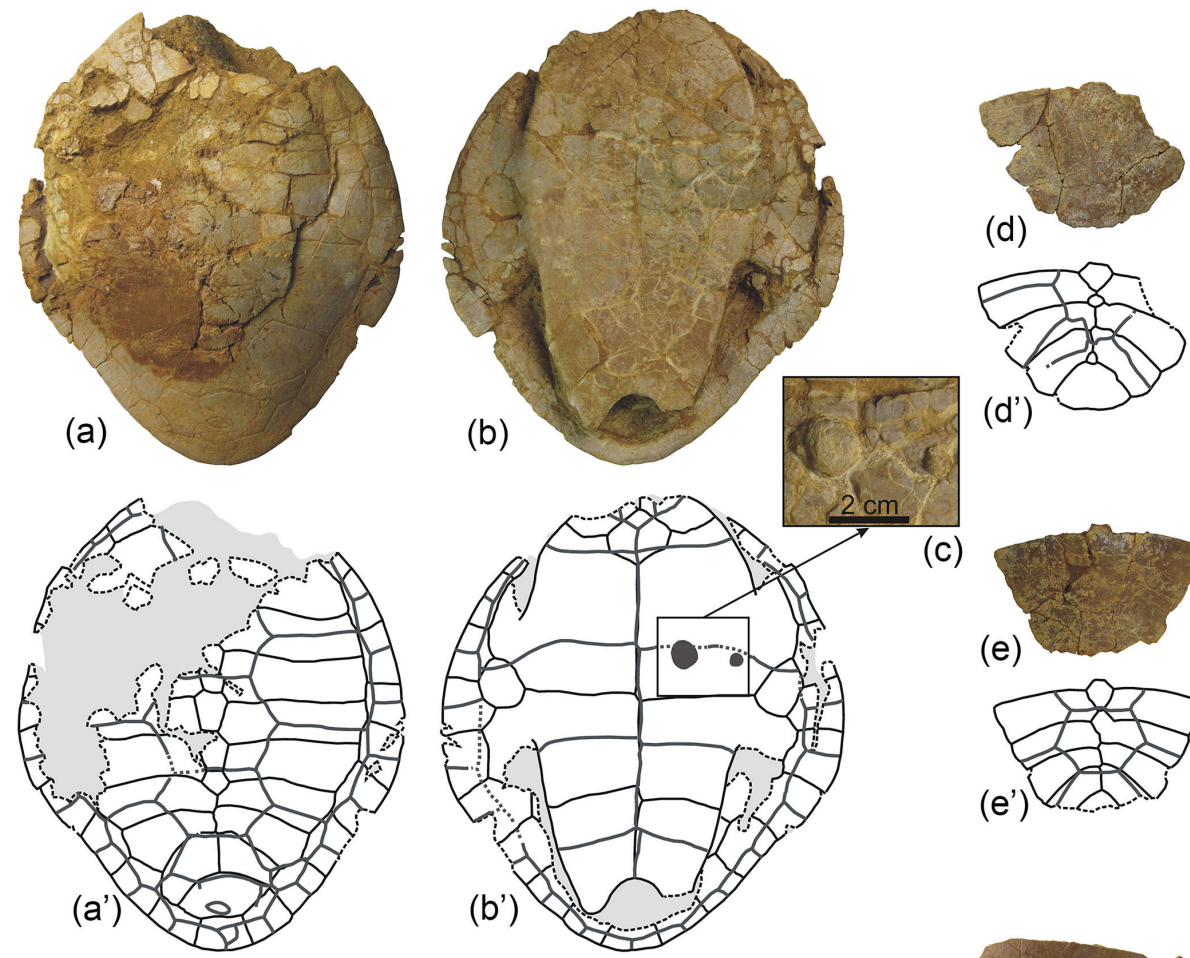

(c)

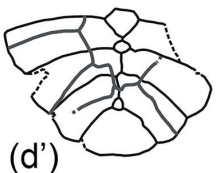

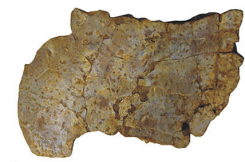

(f)

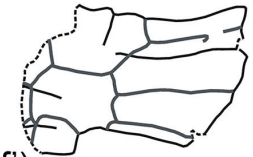

$\left(f^{\prime}\right)$

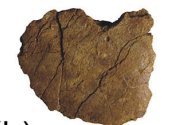

(h)

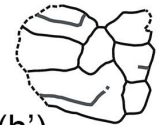

$\left(h^{\prime}\right)$

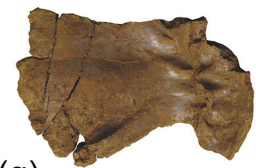

(g)
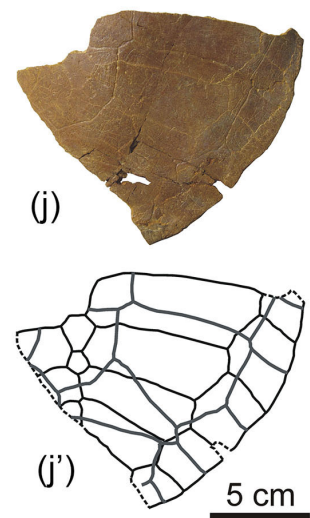

Figure 8. Shells and partial carapaces of Algorachelus peregrinus (Pleurodira, Bothremydidae), from the Cenomanian of Algora (Guadalajara, Spain), which shows anomalies. (a-c) ALG 133, shell in dorsal (a) and ventral (b) views, and detail of a region of the plastron (c). (d) ALG 134, partial posterior half of a carapace, in dorsal view. (e) ALG 135, partial posterior half of a carapace, in dorsal view. (fg) ALG 136, partial posterior half of a carapace, in dorsal (f) and ventral (g) views. (h-i) ALG 137, partial posterior half of a carapace, in dorsal (h) and ventral (i) views. (j) ALG 138, partial posterior half of a carapace, in dorsal view.

Small supernumerary scutes are also present in other specimens, which lack osseous anomalies. Thus, they are identified in the posterior region of the intergular of ALG 75 (Fig. 3b), and in the lateral area of the first vertebral of ALG 83 (Fig. 5c) and third vertebral of ALG 105 (Fig. 6i). A supernumerary anterior right pleural is identified in ALG 82 (Fig. 5b).

Ontogenetic changes in the morphology of the plates, scutes or in that of the carapace are not recognized. A relatively high individual variability was found for Algorachelus peregrinus (Pérez-García, 2016), which is here confirmed, also being identified in other characters, such as, among others, the following: the morphology of the shells (all of them being posteriorly pointed, but some shells, as ALG 75, Fig. 3a-b, being more rounded than others as ALG 77, Fig. 3e-f, more elongated); the width / length ratio of the vertebrals (e.g., these scutes being relatively wide in ALG 80, Fig. 4d; ALG 96, Fig. 5p; ALG 105, Fig. 6i; but relatively long in ALG 95, Fig. 5o; ALG 103, Fig. 6g; ALG 107, Fig. 6k); the morphology of the suture between the epiplastra and the hyoplastra (e.g., rounded in ALG 117, Fig. 7a; but angulated in ALG 76, Fig. 3d); the overlap of the pectoral scutes over the entoplastron (e.g., short in ALG 71, Fig. 2b; ALG 76, Fig. 3d; ALG 80, Fig. 4e; ALG 119, Fig. 7c; long 
in ALG 75, Fig. 3b; ALG 120, Fig. 7d; ALG 123, Fig. 7g; and variable when comparing the left and right region of the same individual in ALG 74, Fig. 2h).

\subsection{Disarticulation patterns for the shells from Algora}

The fossiliferous area of Algora is located in the upper part of the Arenas de Utrillas Formation, in sediments corresponding to sandy coastal deposits of bars and channels. Thus, a stratified sandy interval, composed of sandstones of medium to large grain size, divided into layers $2-3 \mathrm{~m}$ thick, with erosive bases, are recognized there (Segura et al., 2010; Torices et al., 2012; Pérez-García et al., 2017a). ALG-B is located in one of these sandstone layers. Remains of terrestrial vertebrates are also recognized there (e.g., solemydid turtles, sauropod and theropod dinosaurs). However, they are scarce and appear as isolated remains, generally fragmented, because they have been transported. More than $90 \%$ of the remains of macrovertebrates identified there correspond to the coastal turtle Algorachelus. Abundant remains of Algorachelus, generally corresponding to fragments of plates, isolated plates, or isolated fragments of carapaces and plastra are recognized at the base of the fossiliferous layer in which the site ALG-B is located (Fig. 11). In this layer, the concentration of remains is markedly lower outside this basal area. However, the complete or relatively complete shells come from there (Fig. 1a-k). No skull has been found associated with any of these shells. The shells usually do not preserve appendicular elements either. However, the pelvis is usually conserved in situ in the complete shells since, in the pleurodiran turtles, it is sutured with both the carapace and the plastron, its disarticulation generally occurring as a consequence of that between both parts of the shell. Among the shells found in these bar deposits some are identified in the position of maximum stability, that is, with the carapace facing upwards (Fig. 1h, j, and those located on the left side in Fig. 1b); others showing the opposite orientation (Fig. 1c); some with the peripherals of the plastral bridge facing downwards (Fig. 1d-f); as well as specimens in intermediate positions (e.g., that located on the right side in Fig. 1b). These complete shells or those that conserve a high percentage of their plates usually appear isolated, without contact with other remains (e.g., the specimen located on the right side in Fig. 1b, and those in Fig. 1d-h, k). However, one shell located above another has been found (see the left side in Fig. 1b), as well as another above the posterior half of two carapaces, both with an inverse orientation with respect to it (Fig. 1j).

Most of the specimens analyzed here were preserved as buried remains before the excavation, very few being partially exposed. Therefore, scarce individuals have lost osseous elements due to the weathering (some exceptions are the central part of the carapace of the specimen at the top in Fig. 1a-b, as well as much of the carapace of the specimen in Fig. 4a). Most of the breakages in the elements presented here occurred before the burial, as well as the disarticulation processes that affected these specimens scattering their remains. The large number of shells and articulated fragments of carapaces and plastra of Algorachelus peregrinus in the site ALG-B allowed one to define in detail this taxon and to characterize many aspects of its intraspecific variability. But it also allow one to establish the main disarticulation patterns, specimens representing each of these states being recognized (Figs. 9-10).

In most cases, the disarticulation of the shells of Algorachelus peregrinus began with the separation of the carapace and the plastron. This was produced by the dislocation of the bridge peripherals and, in some specimens, also that of those adjacent to them (Fig. 9b, k). These peripherals were separated as isolated plates or articulated with each other and subsequently disarticulated. The pelvis was also separated from the shell at this stage. After that, the disarticulation of other peripherals occurred. In some cases all the peripherals, the pygal and the nuchal were disarticulated before other plates of the carapace (Fig. 9c). In others, this disarticulation was restricted to the anterior peripherals and the nuchal (Fig. 91), or to the posterior peripherals and the pygal (Fig. 9p). The next stage involved the separation by some of the sutures that joined two costal plates to each other, as well as that between the two adjacent neurals (Fig. 9d, i, j, m, q). In many cases the loss of other costals and neurals continued (Fig. 9r), involving, even, the total or partial loss of the peripherals and that of pygal, considering the posterior half of the carapace (Fig. 9e, o). These elements are not always disarticulated in isolation, but examples of a peripheral articulated with a costal are also recognized (Fig. 9o). After the complete loss of the posterior peripherals and of that of the pygal, the sixth to eighth pairs of costals were disarticulated in that order (Fig. 9f-h), the suprapygal remaining isolated. The axial axis of the posterior half of the carapace represented a plane of weakness with respect to that in taxa with a continuous neural series up to the suprapygal, since a large part corresponded to a sub-straight line of suture, defined by the medial contact of the last pairs of costals. In this way, a disarticulation in favor of that plane, sometimes produced before the loss of the posterior peripherals and the pygal (Fig. 9n), and other times after the disarticulation of these elements (Fig. 9g), is identified in several individuals. The anterior half of the carapace also experienced, in some specimens, a disarticulation from a plane close to the axial axis: that corresponding to the suture between the neurals and the costals (Fig. 9v). However, the most common situation was not that but the disarticulation of much of the costals and neurals, with the exception of the first pair of costals and the first neural, which remained in connection with the nuchal and the most anterior peripherals (Fig. 9s). The available record shows that the most anterior region of the carapace was disjointed following different patterns, resulting in different groups of articulated elements (Fig. 9t-aa). 


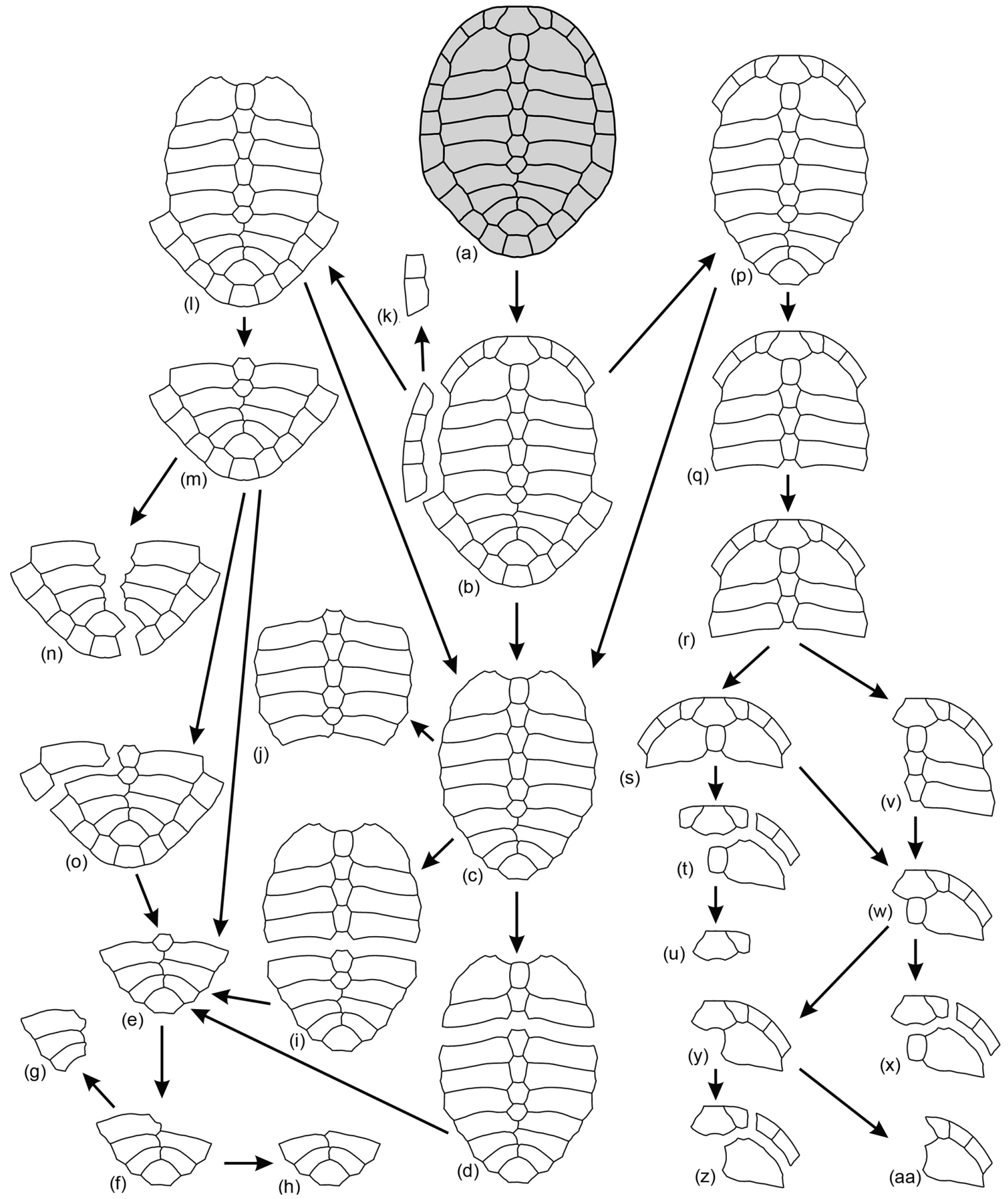

Figure 9. General patterns observed for the disarticulation of the carapaces of Algorachelus peregrinus (Pleurodira, Bothremydidae), based on the specimens from the Cenomanian of Algora (Guadalajara, Spain) 


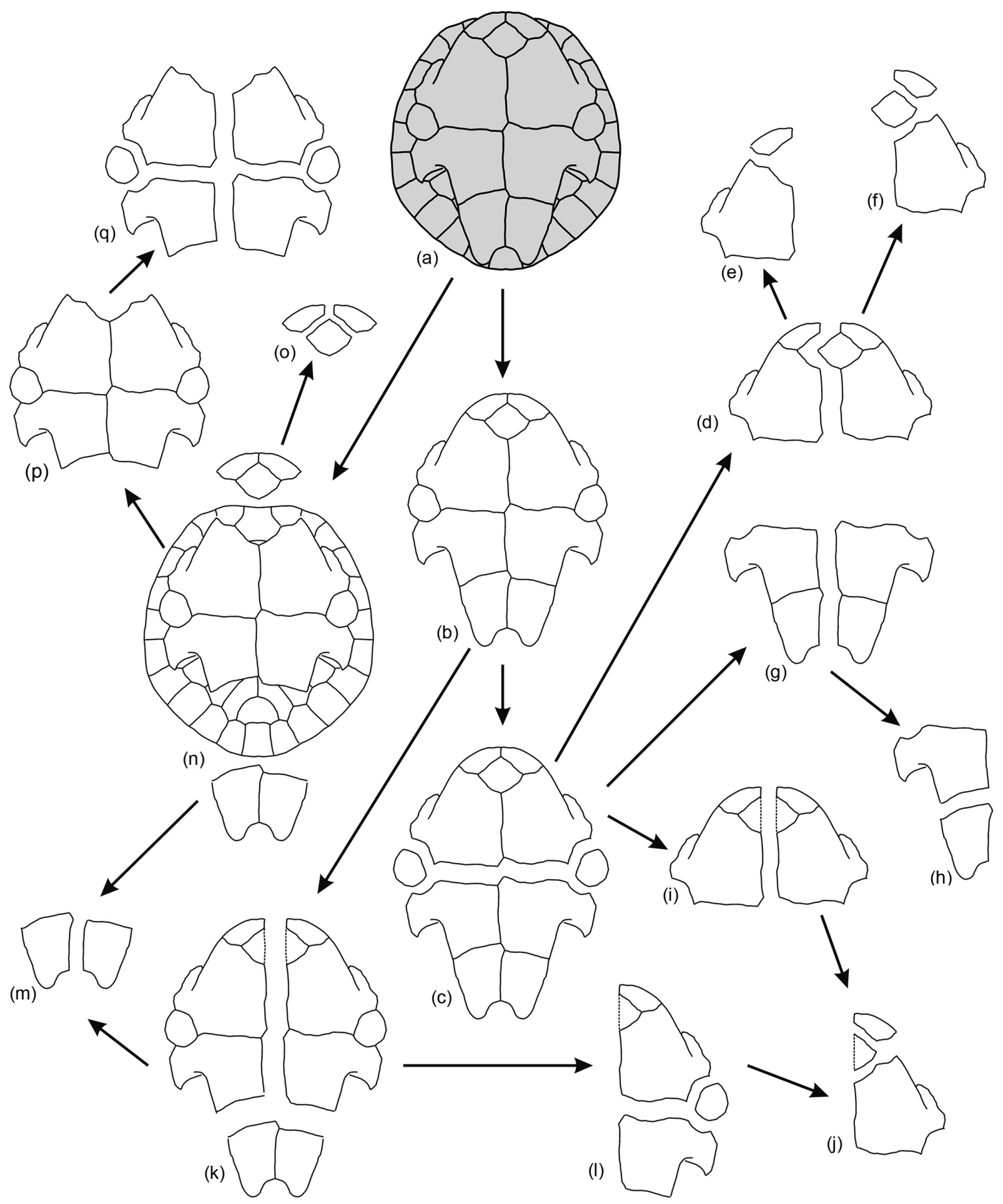

Figure 10. General patterns observed for the disarticulation of the plastra of Algorachelus peregrinus (Pleurodira, Bothremydidae), based on the specimens from the Cenomanian of Algora (Guadalajara, Spain) 
The disarticulation of the bridge peripherals generally occurred before that between the elements of the plastron (Fig. 10b). The main plane of weakness of this element was not the axial plane but that located between the hyoplastra and the hypoplastra, the mesoplastra remaining as isolated plates (Fig. 10c). The posterior half of the plastron (i.e., that composed of the hypoplastra and the xiphiplastra) was separated by the axial plane (Fig. 10g), subsequently the hypoplastron being separated from the xiphiplastron (Fig. 10h). The axial separation of the anterior half (i.e., that corresponding to the epiplastra, entoplastron and hyoplastra) was generated following two patterns. In some cases its trajectory corresponded to a straight line, the break of the entoplastra in two halves approximately symmetrical with each other being made (Fig. 10i). In others, this separation occurred following the medial suture between the epiplastra, that between the hyoplastra, and that between the entoplastron with one of the epiplastra and with one of the hyoplastra, resulting in two asymmetric parts (Fig. 10d). Finally, all these plates were disjointed (Fig. 10e, f, j). Some exceptions to this general pattern of disarticulation of the plastron are recognized. Thus, a shell whose carapace keeps the bridge peripherals of the right side, but not those on the left, and whose plastron was disarticulated from it but in contact, is identified (Figs. 1f, $2 \mathrm{e}-\mathrm{f}$ ). This plastron is preserved as three parts: the xiphiplastra grouped together, and two sets composed of the other regions of the plastron, separated by the axial axis, involving the medial rupture of the entoplastron (Fig. 10k). In addition, another exception is identified (Figs. 1k, 4b-c), corresponding to a specimen that, in spite of not showing disarticulation between the carapace and the plastron, lacks both the xiphiplastra and the anterior plates of the plastron (Fig. 10n). That individual also did not preserve the anterior half of its carapace (Fig. 1k). Different conditions to which different specimens have been subjected (e.g., faster or slower burials, more or less transport, collision with other objects) result in the modification of the parameters relative to the disarticulation patterns. Another example is the carapace of the shell ALG 75 (Figs. 1d-e, 3a-b), which had lost the pygal and the last left peripheral before the burial, but not other elements.

\subsection{Systematic and paleobiogeographical implications}

Two Cenomanian species of Pleurodira were described in Ein Yabrud, Palestine (Middle East) (Haas, 1978a, b). They come from levels now considered as deposited in the early or middle Cenomanian (see Khalloufi et al., 2010, and references there). They are "Podocnemis" parva Haas, 1978a and "Podocnemis" judaea Haas, 1978b. Podocnemis Wagler 1830 is a genus of Podocnemididae now exclusively recognized from the late Miocene to the present of the northern area of South America (Pérez-García, 2017b). Thus, these forms from Palestine were until now considered as attributable to an undetermined genus of Bothremydidae, "Podocnemis" judaea having been identified as a possible ju- nior synonym of "Podocnemis" parva by several authors (see Broin, 1988; Lapparent de Broin and Werner, 1998; Gaffney et al., 2006; Pérez-García, 2016). In fact, Haas (1978b) indicated that he tentatively decided to assign the holotype of "Podocnemis" judaea to a different species, this being done with some reluctance. The synonymy between both species had not until now been justified. The best knowledge about the intraspecific variability of a Cenomanian Bothremydidae provided here allows me to evaluate this hypothesis. Haas (1978b) did not include a diagnosis for "Podocnemis" judaea, but he identified several differences with the specimens previously attributed to "Podocnemis" parva, notified in the discussion of that paper. All these putative differences are recognized here as justifiable by intraspecific variability, as in the case of Algorachelus peregrinus, or as due to the erroneous interpretation of some characters. The most relevant differences recognized between both species by Haas (1978b) were the following: the difference in the number of neurals (compatible with that observed in Algorachelus peregrinus); the supposed difference in the number of posterior costals with medial contact (justified by that different number of neurals, as well as by the erroneous interpretation of the last pair of costals as part of a large suprapygal by Haas, 1978b); the putative difference in morphology, size and disposition of the suprapygal (related to its erroneous interpretation as a larger plate); small differences in the width of the peripherals, their margins being more rounded or more angular (due to both deformation and a small range of individual variability as that recognized for Algorachelus peregrinus); and small details in the morphology of the plastron, the entoplaston and some of the plastral sulci (all of them also recognized here as subject to variability in $\mathrm{Al}$ gorachelus peregrinus). Therefore, the synonymy between these species from Palestine is here justified.

A new generic attribution for "Podocnemis" parva is proposed here. Thus, it is recognized a as member of Algorachelus, the new combination Algorachelus parvus (Haas, 1978a) being proposed. The Iberian species Algorachelus peregrinus differs from Algorachelus parvus by several characters, including the anterior plastral margin reaching a level close to that of the anterior margin of the carapace, the subpentagonal and markedly posteriorly pointed carapace instead of rounded, and its deeper and with rounded lateral margins anal notch. Both species are attributed to the same genus, Algorachelus, sharing the exclusive character combination for their shell proposed by Pérez-García (2016): small shell length; very shallow nuchal notch; wider than long nuchal, its anterior margin being equal to or greater than half of the maximum width of the plate; five, six, or seven neurals; first vertebral on the first pair of peripherals or reaching the second; each scute of the first pair of marginals much wider than long; overlap of the first pair of marginals on no more than half of the nuchal anterolateral margin; medial contact of the humerals; absence of overlap of the pectorals 
on the epiplastra; overlap of the pectorals on the entoplastron; pectoro-abdominal sulci crossing the mesoplastra.

Therefore, the fossil record of this lineage of marine littoral pleurodires of Gondwanan origin is recognized as present in the Middle East in the early or the middle Cenomanian, and in the Iberian Peninsula in the middle to lowermost upper Cenomanian interval (being recognized in the middle Cenomanian of Nazaré, and in the uppermost middle-lowermost upper Cenomanian of Algora) (PérezGarcía, 2016; Pérez-García et al., 2017a). The Iberian findings have been recognized as evidence of the oldest dispersal event of Pleurodira from Gondwana to Laurasia so far known. Only another member of Bothremydidae was defined in the pre-Santonian record of Laurasia, "Paiutemys" tibert Joyce, Lyson and Kirkland, 2016, from the uppermost Cenomanian of Utah (United States). It has recently been recognized as a taxon closely related to Algorachelus peregrinus, this lineage of Bothremydidae reaching the west area of the Atlantic Ocean at least in the late Cenomanian (Pérez-García et al., 2017a).

Because Algorachelus peregrinus and "Paiutemys" tibert were simultaneously published on the online final versions which fulfils all requirements of the International Code of Zoological Nomenclature (28 September 2016) (see Krell and Pape, 2015), none of them was considered in the diagnosis of the other taxon (the date of both submission and acceptance of the manuscript where the Iberian species was defined is earlier than those of the North American, the first one having been submitted on 30 March 2016, and accepted on 15 July 2016; and that of "Paiutemys" tibert was submitted on 28 April 2016, and accepted on 29 August 2016). "Paiutemys" tibert is known by a single and relatively complete shell (Joyce et al., 2016). Pérez-García et al. (2017a) indicated that probably none of the characters used in the diagnosis of this taxon differ from those of Algorachelus peregrinus. This hypothesis is confirmed here, thanks to the study of abundant and well-preserved material from the type locality of this Iberian species. Thus, both share the same nuchal notch morphology; the previously indicated variability for the overlap of the pectoral scutes on the entoplastron of the Iberian form shows that of the North American species is not different; the pectoral scutes do not overlap onto the epiplasta of any of them; the reduction of the anterior plastral lobe is present in both forms; the surface sculpture has been recognized as equal among them (Pérez-García et al., 2017a). Joyce et al. (2016) included in the diagnosis of this North American taxon the presence of contact of the axillary buttresses with the second pair of costals. However, they indicated that this degree of development of these buttresses could not be demonstrated. Thus, the presence of this contact had been inferred from the identification of apparent symmetrically raised areas on the anterior dorsal region of the carapace. Similar raised areas on the postero-lateral region of the first pair of costals and the anterolateral of the second pair are similar to those observed in other partially crushed pleu- rodiran specimens, as for example in several specimens of the podocnemidid Neochelys Bergounioux, 1954 (see PérezGarcía, 2015; Cadena, 2015), and in one of the specimens of the Bothremydidae Algorachelus parvus (see fig. 3 in Haas, 1978b). In fact, the development of the axillary buttresses under the second pair of costals is recognized as for all known members of the crown group Pleurodira. Therefore, that inference cannot be validated.

In spite of the presence of a supernumerary nuchal scute in contact with the first pair of marginals of the holotype and only known specimen of "Paiutemys" tibert (see fig. 3a in Joyce et al., 2016), neither those marginals nor the nuchal plate seems to show anomalies. Following Pérez-García et al. (2017a), the absence of noticeably wider than long nuchal, and the first pair of marginals not being much wider than long, showing a relatively long overlap on the anterolateral margins of this plate, are two characters not included in the original diagnosis of "Paiutemys" tibert but identified here as not shared with Algorachelus peregrinus, allowing the support of the validity of this North American species. Because this poorly represented species shares the other characters of the exclusive combination that diagnoses the genus Algorachelus, belonging to the same lineage of Cenomanian littoral bothremydids, the new combination Algorachelus tibert (Joyce et al., 2016) is proposed following the Article 24.2.2. of the International Code of Zoological Nomenclature (i.e., the precedence of the names and acts being fixed by "the First Reviser"). The study of other specimens found in Algora and currently under preparation, highlighting that of several complete skulls, will allow one to amend the diagnosis of this genus through the inclusion of new characters, as well as that of each of the three species, providing more information on the systematics of this form.

\section{Conclusions}

Abundant and well-preserved remains of shells and partial shells of the coastal turtle Algorachelus peregrinus, found as consequence of the first systematic excavation of relatively long duration carried out in its type locality (the Cenomanian site of Algora, in central Spain), are presented here. These findings include the most complete shells hitherto known for this species. In fact, it is recognized as the best represented bothremydid in the European record, this collection also including other elements as several complete and wellpreserved skulls.

The analysis of the new complete and partial shells presented here allows me to provide new data on the anatomy and intraspecific variability of the Iberian species Algorachelus peregrinus. In addition, the abundance of remains, corresponding to both complete shells as well as numerous partial carapaces and plastra, allows me to analyze how the disarticulation on the different plates occurred, several patterns being established. Several anomalies are identified, af- 
fecting both the plates and the scutes, independently in some individuals, or involving both elements in others.

The increase in the knowledge about the shell of this Iberian Cenomanian species allows the evaluation of the validity of other shell taxa of Bothremydidae of the same stage. The identification of "Podocnemis" judaea, from the early or middle Cenomanian of Palestine (Middle East), as a junior synonym of "Podocnemis" parva, from the same locality and horizon, is justified. "Podocnemis" parva is recognized as a closely related form to Algorachelus peregrinus, the new combination Algorachelus parvus being proposed. The bothremydid "Paiutemys" tibert, from the uppermost Cenomanian of Utah (United States), is also identified as a representative of Algorachelus, the new combination Algorachelus tibert being established. Therefore, close biogeographical relationships are recognized among these Cenomanian turtles from the Middle East, Europe and North America, evidencing the relative fast and of wide geographical distribution dispersal event carried out by this Pleurodira, being recognized as the oldest dispersal for this lineage of Gondwanic origin to Laurasia.

Data availability. The specimens studied here are deposited in the Museo de Paleontología de Castilla-La Mancha (Cuenca, Spain).

Competing interests. The author declares that he has no conflict of interest.

Special issue statement. This article is part of the special issue "Secondary adaptation of tetrapods to life in water - Proceedings of the 8th International Meeting, Berlin 2017'. It is a result of the 8th International Meeting on the Secondary Adaptation of Tetrapods to Life in Water, Berlin, Germany, 3-8 April 2017.

Acknowledgements. This research has been funded by the Ministerio de Economía, Industria y Competitividad (FPDI-2013-18986, IJCI-2016-30427 and CGL2015-68363-P), especially by the Viceconsejería de Cultura of the Consejería de Educación, Cultura y Deportes of Castilla-La Mancha (SBPLY/16/180801/000021). The author thanks Montserrat Sanz and her family for the cooperation that has been fundamental to the development of this project, and numerous colleagues involved in both the excavations and in different stages of the activity carried out in Algora, especially Marcos Martín, Andrea Guerrero, Carlos de Miguel, Francisco Ortega, Fátima Marcos and the other members of the Grupo de Biología Evolutiva of the UNED. The author thanks editor Florian Witzmann, an anonymous reviewer, and Walter Joyce for comments and suggestions.

Edited by: Florian Witzmann

Reviewed by: Walter Joyce and one anonymous referee

\section{References}

Batsch, G. C.: Versuch einer Anleitung, zur Kenntniß und Geschichte der Thiere und Mineralien, Akademie Buchhandlung, Jena, 1788.

Baur, G.: Notes on some little known American fossil tortoises, P. Acad. Nat. Sci. Phila., 43, 411-430, 1891.

Bergounioux, F. M.: Les Chéloniens fóssiles des terrains tertiaires del Vénétie, Memoire degli istituti di Geologica e Mineralogia dell'Università di Padova, 18, 1-115, 1954.

Broin, F. de: Les tortues et le Gondwana. Examen des rapports entre le fractionnement du Gondwana au Crétacé et la dispersion géographique des tortues pleurodires à partir du Crétacé, Studia Salmanticensia, Studia Palaeocheloniologica, 2, 103-142, 1988.

Cadena, E.: A global phylogeny of Pelomedusoides turtles with new material of Neochelys franzeni Schleich, 1993 (Testudines, Podocnemididae) from the middle Eocene, Messel Pit, of Germany, PeerJ, 3, 1-27, 2015.

Cope, E. D.: On the limits and relations of the Raniformes, P. Acad. Nat. Sci. Phila., 16, 181-183, 1864.

Cope, E. D.: On the origin of genera, P. Acad. Nat. Sci. Phila., 20, 242-300, 1868.

Gaffney, E. S., Tong, H., and Meylan, P. A.: Evolution of the sidenecked turtles: the families Bothremydidae, Euraxemydidae, and Araripemydidae, B. Am. Mus. Nat. Hist., 300, 1-700, 2006.

Haas, G.: A Cretaceous pleurodire turtle from the surroundings of Jerusalem, Isr. J. Zool., 27, 20-33, 1978a.

Haas, G.: A new turtle of the genus Podocnemis from the lower Cenomanian of "Ein Yabrud", Isr. J. Zool., 27, 169-175, 1978 b.

Joyce, W. G., Lyson, T. R., and Kirkland, J. I.: An early bothremydid (Testudines, Pleurodira) from the Late Cretaceous (Cenomanian) of Utah, North America, PeerJ, 4, e2502, https://doi.org/10.7717/peerj.2502, 2016.

Khalloufi, B., Zaragüeta-Bagils, R., and Leliévre, H.: Rhombichthys intoccabilis, gen. et sp. nov. (Ellimmichthyiformes, Clupeomorpha, Teleostei), from the Cenomanian (Upper Cretaceous) of Ein Yabrud, Middle East: anatomical description and phylogenetic implications, J. Vertebr. Paleontol., 30, 57-67, 2010.

Krell, F.-T. and Pape, T.: Electronic publications need registration in ZooBank to be available, Bull. Zool. Nomencl., 72, 245-251, 2015.

Lapparent de Broin, F. de: The European turtle fauna from the Triassic to the Present, Dumerilia, 4, 155-216, 2001.

Lapparent de Broin, F. de and Werner, C.: New Late Cretaceous turtles from the Western Desert, Egypt, Ann. Paleontol., 84, 131214, 1998.

Pérez-García, A.: Nuevos datos sobre la tortuga pleurodira del Eoceno medio de Alemania Neochelys franzeni: Implicaciones derivadas del hallazgo de un ejemplar juvenil, Geogaceta, 57, 71-74, 2015.

Pérez-García, A.: A new turtle taxon (Podocnemidoidea, Bothremydidae) reveals the oldest known dispersal event of the crown Pleurodira from Gondwana to Laurasia, J. Syst. Palaeontol., 15, 1-23, 2016.

Pérez-García, A.: The Iberian fossil record of turtles: an update, J. Iber. Geol., 43, 155-191, 2017a.

Pérez-García, A.: New information and establishment of a new genus for the Egyptian Paleogene turtle "Stereogenys" libyca (Podocnemididae, Erymnochelyinae), Hist. Biol., 2017, 1-10, https://doi.org/10.1080/08912963.2017.1374383, 2017b. 
Pérez-García, A., Segura, M., Bardet, N., Barroso-Barcenilla, F., Cambra-Moo, O., Ortega, F., and Torices, A.: Nuevos fósiles de vertebrados en los niveles cenomanienses de Algora (Guadalajara, España), in: libro de resúmenes del V Congreso del Cretácico de España, Instituto Geológico y Minero de España, Madrid, 66, 2013.

Pérez-García, A., Antunes, M. T., Barroso-Barcenilla, F., Callapez, P. M., Segura, M., Soares, A. F., and Torices, A. A bothremydid from the middle Cenomanian of Portugal identified as one of the oldest pleurodiran turtles in Laurasia, Cretaceous Res., 78, 6170, 2017a.

Pérez-García, A., Lapparent de Broin, F. de, and Murelaga, X.: The Erymnochelys group of turtles (Pleurodira, Podocnemididae) in the Eocene of Europe: new taxa and paleobiogeographical implications, Palaeontol. Electron., 20, 1-28, 2017b.
Segura, M., Barroso-Barcenilla, F., Cambra-Moo, O., Pérez-García, A., and Torices, A.: Introduction to the new Cenomanian palaeontological site "Algora" (Upper Cretaceous, Guadalajara, Spain), Carnets de Géologie, 7, 232-233, 2010.

Torices, A., Barroso-Barcenilla, F., Cambra-Moo, O., Pérez-García, A., and Segura, M.: Palaeontological and Palaeobiogeographical implications of the new Cenomanian site of Algora, Guadalajara, Spain, Cretaceous Res., 37, 231-239, 2012.

Wagler, J.: Natürliches System der Amphibien, mit Voragehender Classification der Säugethiere und Vögel, Cotta, Munich, 1830. 